\title{
A new species of Xantharus Andronov, 1981 (Copepoda: Calanoida) from the mesopelagic zone of the Antarctic Ocean
}

\author{
K. Schulz* \\ Zoologisches Institut und Museum, Universität Hamburg, Martin-Luther-King-Platz 3, \\ D-20146 Hamburg, Deutschland * *
}

\begin{abstract}
Xantharus renatehadssae sp. nov. is described from a female taken at mesopelagic depth of the Antarctic Sound. This is the second species within the genus to be described and the first record of Xantharus in the southern hemisphere. A diagnosis of the genus is presented. Primarily, the structure of the maxillar aesthetascs showed that Xantharus belongs to the Scolecitrichidae, and not to the Phaennidae as was originally proposed. Its most outstanding generic feature relates to the structure of the distal segments of the short antennule with some plesiomorphic conditions retained by particular mouthparts.
\end{abstract}

\section{INTRODUCTION}

Recently, the monotypic genus Xantharus has been established for a new species, $X$. formosus, collected from subsurface waters of the Northwest Atlantic Ocean off North America (Andronov, 1981). The species was described from both male and female specimens. However, Andronov's interpretation of the new genus as belonging to the calanoid family Phaennidae raises considerable doubt since a key feature of Phaennidae, the special nature of the sensory filaments located at the endopod of maxilla, seems to be absent in this species and thus would preclude its inclusion in this family as Bradford et al. (1983) remarked. Instead, this genus appears to possess diagnostic criteria established for the family Scolecitrichidae.

This paper describes a second species of Xantharus based on a single female from a mesopelagic haul taken in the Antarctic Sound between the tip of the Antarctic Peninsula and Joinville Island and made available to me by Dr. Sigrid Schiel (Alfred-WegenerInstitut für Polar- und Meeresforschung, Bremerhaven), whereby its affiliations to „bradfordian " families (Ferrari \& Markhaseva, 1996) are considered, i.e. those taxa occupying sensory filaments (aesthetascs) mainly on the maxillar endopod.

\footnotetext{
- Member of the Taxonomy Group at the Biologische Anstalt Helgoland. Notkestr. 31, D-22607 Hamburg, Deutschland

- Address for correspondence

(c) Biologische Anstalt Helgoland, Hamburg
} 


\section{MATERIALS AND METHODS}

The plankton sample containing a specimen of Xantharus renatehaassae sp. n. was collected during the Joint Biological Expedition of the Federal Republic of Germany and the United Kingdom (30th January-3rd March 1982) on RRS "John Biscoe", using a vertically towed Nansen closing net of $200 \mu \mathrm{m}$ mesh. Additional information on the expedition and the collections may be found in Piatkowski (1983). The holotype was dissected in lactic acid and the dissected parts were placed in polyvinyl-lactophenol mounting medium. All drawings were prepared using a camera lucida on a Zeiss Axioskop interference microscope. The terminology used in the descriptions follows Huys \& Boxshall (1991). Measurements are of the individual fixed in formalin and transferred to glycerin. Lengths of prosome and urosome used in the descriptive text were measured mid-dorsally from the anterior tip of the cephalon to the posterior dorsal articulation of pediger 5 and genital double somite and from there to the posterior end of the caudal rami, respectively. Material is deposited in the Zoologisches Museum der Universität Hamburg $(\mathrm{ZMH})$.

\section{TAXONOMY}

\section{Family Scolecitrichidae Sars, 1902}

\section{Genus Xantharus Andronov, 1981}

This genus was established by Andronov (1981) to accommodate a new species, Xantharus formosus, found in the western North Atlantic off North America. Both male and female were encountered.

D i a g nos is: Small scolecitrichids of less than $1.5 \mathrm{~mm}$ total length. Prosome in dorsal view ovoid; rostrum present, bifurcated; first pediger fused to cephalosome, pedigers 4 and 5 fused. Female urosome 4 -segmented, short, less than one-third the length of prosome; fourth somite very short. In both sexes antennule short, not reaching to distal part of prosome; female antennule 24-segmented, free distal segments 19-24 relatively short, length of segment 19 less than one-half of free segment 18, both armed with a very long seta. Cutting blade of mandible with set of slender teeth ventrally; basis armed with 3-4 setae, first endopodal segment carrying 3 setae. Maxillule with praecoxal arthrite bearing 3 posterior setae, coxal endite and first basal endite with 2 and 4 setae, respectively; exopod with 8 setae. First praecoxal endite of maxilla with 4-5 setae, basal endite lacking aesthetascs; endopod bearing 5 small brush-like and 3 long vermiform aesthetascs. Male mouthparts not reduced. Leg 1 with endopod carrying lateral lobe; third exopodal segment of legs 2-4 armed with coarsely serrate distal spine. Female fifth legs symmetrical, 3 -segmented, uniramous, each ending in 2 points. Male fifth legs slightly asymmetrical, with 1-segmented, simple, endopods and 3-segmented exopods tapering into sharp point distally.

Ty pe species: Xantharus formosus Andronov, 1981, by monotypy.

Other species: $X$. renatehaassae to be described below.

Xantharus renatehaassae sp. nov. (Figs 1-3)

Material examined: One female collected during the Joint Biological Antarctic Expedition on board RRS "John Biscoe", cruise 03, station 1040, haul 51 (63⒉ $27.0^{\prime}$ S, 
$56^{\circ} 42.0^{\prime} \mathrm{W}$ ), taken on 11 th February $1982,02.30-02.55$ hours GMT, at a depth of 1040-500 m, water depth $1050 \mathrm{~m}$; collected by S. Schiel.

$\mathrm{H}$ ol ot y p e: Female, total length $1.36 \mathrm{~mm}$, dissected and mounted on slides (ZMH Reg. no. K-37579).

Description: Adult female. Body robust (Figs $1 \mathrm{~A}, \mathrm{~B}$ ), total length $1.36 \mathrm{~mm}$, length/width ratio 2.4. Prosome 4-segmented and oval in dorsal view, about 3.5 times longer than urosome. First pediger incorporated into cephalosome; fourth and fifth pedigers fused. Posterior corner of prosome produced distally and ending laterally in an angular pointed lobe reaching two-thirds length of genital double-somite. Rostrum (Fig. 1 C, D) composed of two short conical prongs lacking filaments and directed posteroventrally. Urosome 4-segmented (Fig. $1 \mathrm{E}$ ), slightly less than one-third length of prosome (measured mid-dorsally). Urosomites, perhaps excepting the anal somite, at rear margins bordered by dentate frill. Genital double-somite (Fig. 1 F) about as long as wide, only very slightly projecting ventrally, and slightly longer than rest of urosome (excluding caudal rami); in lateral view seminal receptacles only very faintly visible, proximally a narrow digitate tube leading dorsally and bending anteriorly and ending in globular vesicle. Second free urosomite about as long as third although appearing shorter due to larger part being telescoped into genital double somite. Anal somite very short and hardly visible at all, about one-tenth the length of preceding somite, measured laterally. Caudal rami symmetrical, about 1.3 times longer than wide, inner margin bearing setules; caudal rami armed with 6 setae, 1 of these small and curved inwards originating from lateral margin subdistally and implanted on small socket; 4 large setae distally (all broken), and 1 short ventral seta implanted near inner edge of caudal ramus.

Antennules (Fig. 2 A, A'): slightly asymmetrical in present specimen, probably caused by previous regeneration following damage to distal segments of right appendage. Left antennule comprising 24 free segments, relatively short and extending only to middle of second pediger. Armature fusion patterns as follows: 1-3, fused ancestral segments II-IV-6 + aesthetasc, V-2 + aesthetasc, VI-2, VII-2 + aesthetasc, VIII-2, IX-2 + aesthetasc, fused ancestral segments X-XI-4 + aesthetasc, XII-1,XIII-1, XIV-2 + aesthetasc, XV-1, XVI-2 + aesthetasc, XVII-1, XVIII-2, XIX-1, XX-2, XXI-1 + aesthetasc, XXII-1, XXIII-1, XXIV-2, XXV-2, XXVI-2, apical segment (corresponding to fused ancestral segments XXVII and XXVIII) $5+$ aesthetasc. Free (actual) segments 11 to 18 (corresponding to ancestral segments XIV to XXI) subequal in length, measured on hind margins, whereas segments 19 to 21 distinctly shortened: segment 19 very short, about half the length of preceding, measured on posterior margins, and protruding on outer distal edge; segments 19 and 20 each equipped with 1 extra long seta; apical segment relatively narrow compared with preceding segments and armed with rather small aesthetasc.

A n te n n a (Fig. $1 \mathrm{G}$ ): with coxa and basis mostly fused, armed with 1 and 2 setae respectively; endopod 2-segmented, first endopodal segment with 2 unequal setae subdistally; second segment with 8 and 7 setae on subapical and apical lobes, respectively; exopod slightly longer than endopod and composed of 6 free segments bearing a total of 9 setae.

Mandible (Fig. 2 B, C): coxa slender carrying gnathobase with 4 deeply incised, multicuspid teeth ventrally, remaining 4 teeth distinctly smaller plus a long dorsal seta; basis with 3 plumose setae proximally and an additional, naked seta of smaller size; 


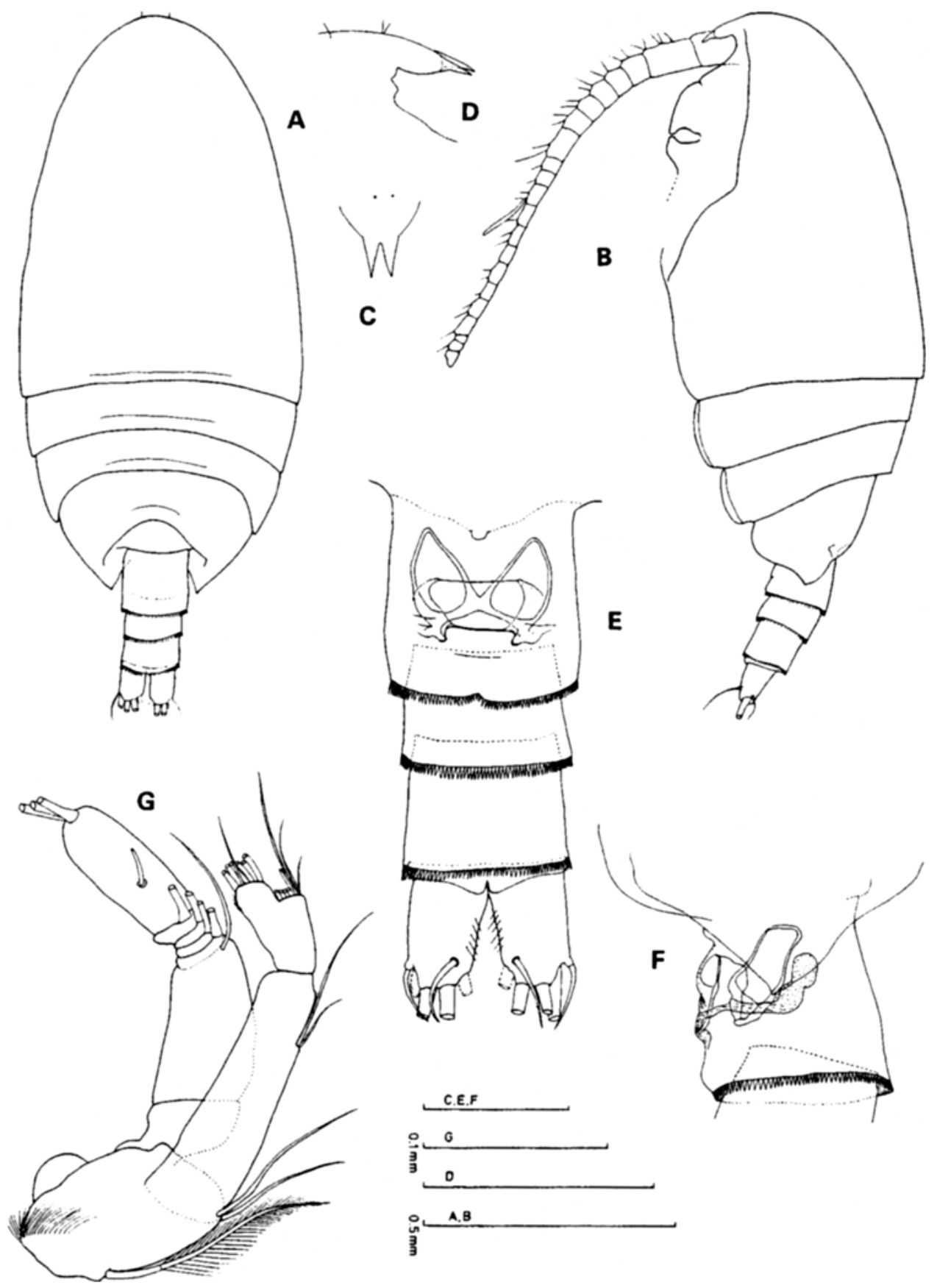

Fig. 1. Xantharus renatehaassae sp. nov., female. A: Habitus, dorsal. B: Habitus, lateral, showing slightly damaged right antennule. C: Rostrum, ventrofrontal. D: Rostrum, lateral. E: Urosome, ventral. F: Genital double-somite, lateral. G: Antenna 


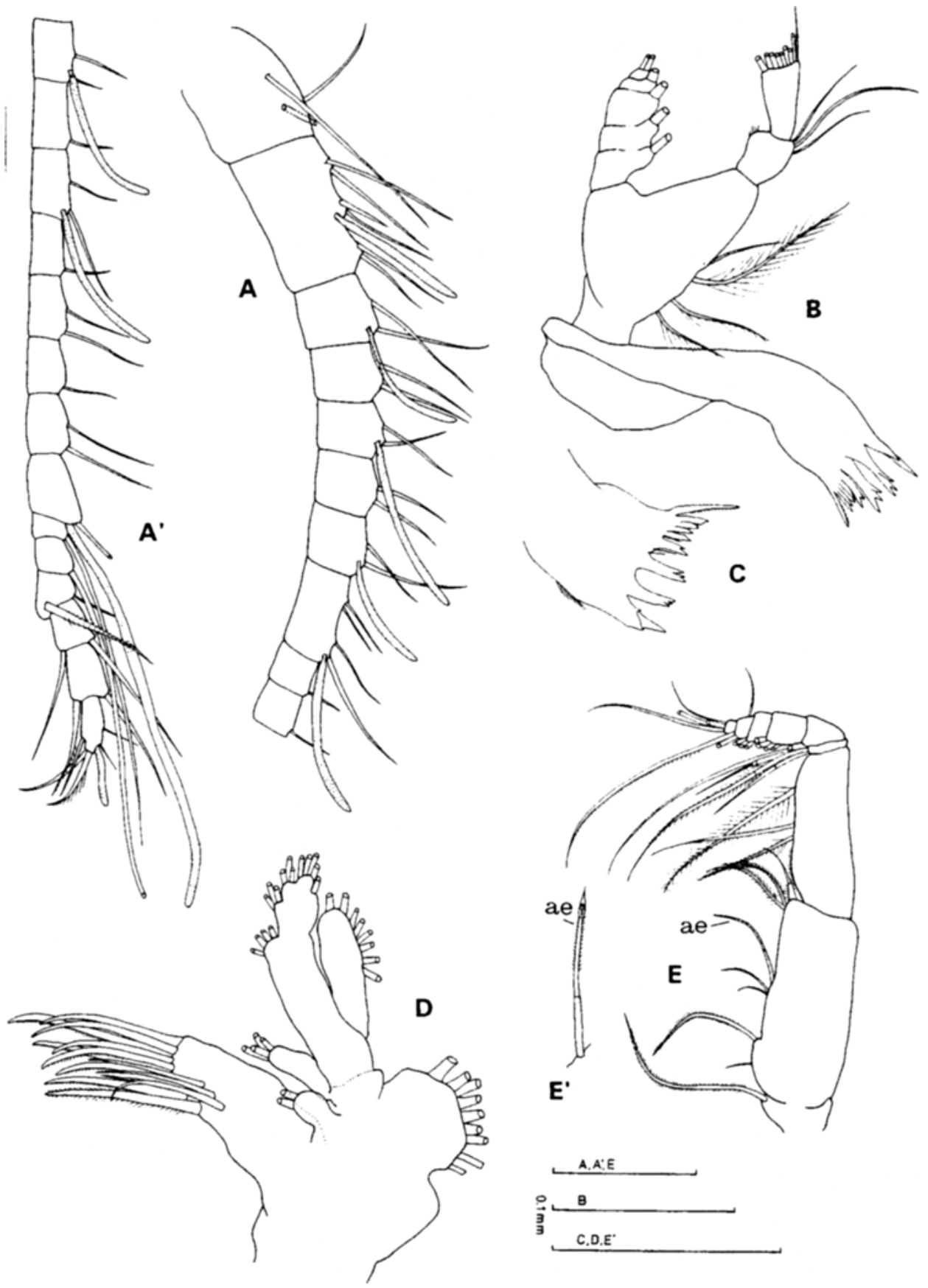

Fig. 2. Xantharus renatehaassae sp. nov., female. A: Antennule, articulated segments 1-10. A': Antennule, articulated segments 11-24. B: Mandible. C: Mandible, gnathobase. D: Maxillule. E: Maxilliped, ae= aesthetasc. E': Aesthetasc of maxillipedal coxal endite 3, other body side 


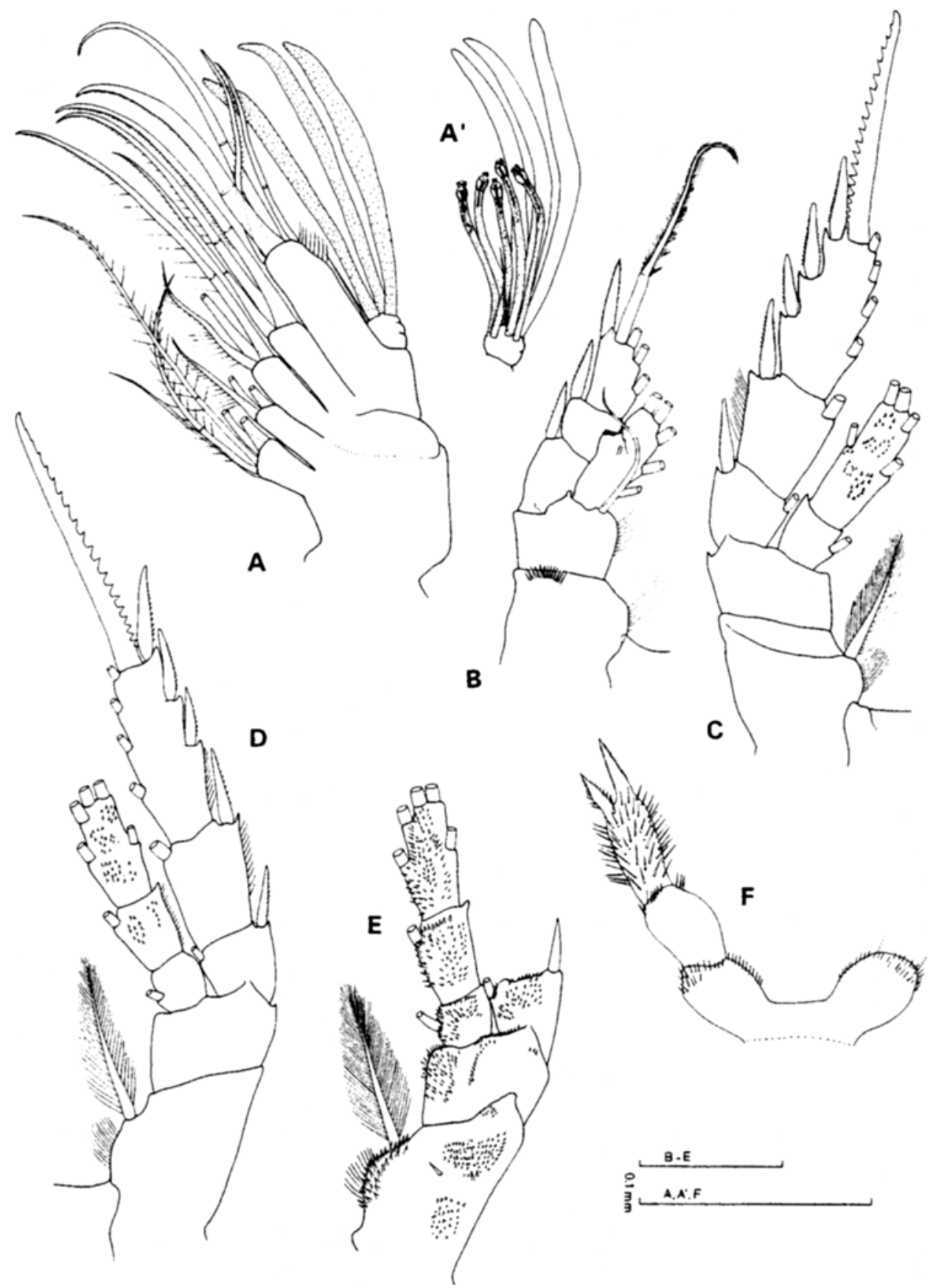

Fig. 3. Xantharus renatehaassae sp. nov., female. A: Maxilla, armature of endopod not entirely shown. A': Maxillar endopod. B: Leg 1, anterior. C: Leg 2, posterior. D: Leg 3, posterior. E: Leg 4, posterior. F: Fifth pair of legs, posterior; left partly detached 
endopod 2-segmented, first segment having 3 distolateral setae, second endopodal segment bearing 9 setae distally; exopod with 6 setae.

Maxillule (Fig. 2 D): arthrite of praecoxa armed with 9 large spines plus 1 slender seta on distal margin, and 3 posterior setae; endite and epipodite of coxa with 2 and 9 setae, respectively; proximal and distal endites of basis each armed with 4 setae; endopod fused to basis and armed with 3,3, and 5 setae; exopod elongate and slender bearing 8 setae.

$\mathrm{Maxilla}$ (Fig. $3 \mathrm{~A}, \mathrm{~A}^{\prime}$ ): proximal praecoxal endite armed with 5 unequal setae, distal praecoxal and both coxal endites bearing 3 unequal setae each, basis with large endite carrying a strong, curved spine/seta and 3 smaller unequal setae; endopod equipped with 1 small, slender seta and a total of 8 aesthetascs; 5 of these distinctly smaller than the rest and carrying brush-like globular tips; remaining 3 about two times longer and of unspecialized, worm-like structure.

Maxilliped (Fig. 2 E, E') slender; praecoxa and coxa indistinctly separated, with a total of 4 endites carrying 1, 2 ( 1 very small), 2 and 1 aesthetasc, and 3 setae, from proximal to distal; of these, praecoxal seta longest; aesthetasc differently developed on both sides of the body, with one aesthetasc having seta-like structure, the other (Fig. 2 E') carrying slightly plumose distal half and specialized brush-like tip. Basis with marginal row of setules in proximal third, and 3 unequal setae more distally; endopod 6-segmented, setal formula $2,4,4,3,3,4$.

$\mathrm{Sw}$ im ming legs 1 to 4: biramous, with segmentation pattern typical of the superfamily Clausocalanoidea; armature as follows (data of leg 4 exopodal segments 2 to 3 have been supplemented because of mutilated segments 2 and 3):

\begin{tabular}{|c|c|c|c|c|}
\hline & Coxa & Basis & Exopod & Endopod \\
\hline Leg 1 & $0-0$ & $0-1$ & $1-0 ; 1-1 ; 1,1,3$ & $0,2,3$ \\
\hline Leg 2 & $0-1$ & $0-0$ & $\mathrm{I}-1 ; \mathrm{I}-1 ; \mathrm{III}, \mathrm{I}, 4$ & $0-1 ; 1,2,2$ \\
\hline Legs $3+4$ & $0-1$ & $0-0$ & I-1; I-1; III,I,4 & $0-1 ; 0-1 ; 1,2,2$ \\
\hline
\end{tabular}

Le g 1 (Fig. 3 B): coxa with distal row of spinules on anterior face; basis carrying 1 curved seta on distomedial edge; endopod with outer lobe omamented with row of setules distally; outer spines of exopodal segments 1 to 3 ornamented with small spinules. Le g 2 (Fig. $3 \mathrm{C}$ ): endopodal segment 2 with short spinules on posterior face; outer spines of exopodal segments 1 to 3 very slightly subequal in size, distal spines of segments 2 and 3 being largest; apical spine of exopodal segment 3 relatively coarsely serrate carrying about 18 teeth. Leg 3 (Fig. 3 D): endopodal segments 2 and 3 ornamented with spinules posteriorly; exopodal segment 3 with distal outer spine larger than remaining spines of segments 1 to 3 , and carrying coarsely serrate apical spine having about 20 teeth. L e g 4 (Fig. 3 E): mutilated, with patches of spinules on every segment; exopod broken distal to segment 1.

Fif th legs (Fig. 3 F): uniramous, 3-segmented, joined by intercoxal sclerite; coxa and basis ornamented with spinules distally; third segment (exopod) slender, about 3.5 times longer than wide and covered by long spinules particularly on posterior face; distal margin armed with 2 spine-like protrusions with the apical larger than the outer, both ornamented with marginal denticles and tapering distally.

Etymology: In honour of the late Dr. Renate Haass, my colleague in the Taxonomy Group at the Biologische Anstalt Helgoland, distinguished for her detailed 
contributions to the systematics and zoogeography of euphausiid and hyperiid crustaceans.

Additional note on the occurrence of Xantharus renatehaassae. - The station in the Antarctic Sound from which the new species was collected is remarkable for its extraordinarily high copepod species diversity (S. Schiel, pers. comm.), as was demonstrated also by the co-occurrence with another then new species from a "bradfordian" family, Neoscolecthrix antarctica, described by my retired former colleague, Kuni Hulsemann (1985).

R e m a r k s: Dr. N. Vyshkvartzeva re-examined the type material of X. formosus and found that, contrary to the information given by Andronov (1981), the endopodal segment 1 of mandible carries 3 setae (instead of 2) the maxillular arthrite of maxillule is armed with 3 posterior setae (instead of 2), and 9 strong edge setae, and the endopod of maxilla bears 3 worm-like and 5 brush-like aesthetascs with small heads.

$X a n t h a r u s$ renatehaassae is closely related to $X$. formosus; it differs, however, in its larger size, the shape of the rostrum as well as in the posterior corner of prosome, and in the armature both of mouthparts and fifth legs. In $X$. renatehaassae the rostrum bears conical prongs distally but lacks filaments, and the prosome carries an angular, pointed lobe in contrast to a rounded lobe in $X$. formosus. In $X$. renatehassae the mandibular basis occupies 4 setae, but it occupies 3 in $X$. formosus. The endopod of maxillula carries 11 setae contrary to 10 setae in $X$. formosus. In $X$. renatehaassae the proximal praecoxal endite of maxilla bears 5 setae but only 4 in $X$. formosus, and the fifth legs carry a bifurcated distal part of the exopod whereas in $X$. formosus they carry a bifurcation in addition to a large inner distal spine.

Andronov (1981) placed the genus Xantharus in the Phaennidae, although he could not precisely check the structure of the maxillar endopodal elements, a key characteristic of the five "bradfordian" families (Ferrari \& Markhaseva 1996) which encompass all taxa possessing aesthetascs instead of normal setae on the endopod of maxilla, and the shape of these aesthetascs often is a characteristic diagnostic of the different families. According to Bradford et al. (1983), the Phaennidae display an endopod having 1 worm-like and 7 brush-like aesthetascs, whereas in Scolecitrichidae 3 worm-like and 5 brush-like filaments are diagnostic. Following early re-examination of the type, Vyshkvartzeva (1989) stated that this species should be incorporated in Scolecitrichidae on account of aesthetasc morphology, and quite recently this author (pers. comm.) confirmed the structure of the endopodal aesthetascs of maxilla as being composed of 3 long worm-like and 5 shorter brush-like aesthetascs tipped with small heads and, thus, this combination matches precisely the essential diagnostic character for the family Scolecitrichidae as given by Bradford et al. (1983). This interpretation is further supported by the information derived from the present examination of the new Antarctic species of Xantharus.

Among scolecitrichids Xantharus retains an unusual condition in the position of the small dorsolateral seta of caudal ramus; remaining members of the superfamily Clausocalanoidea display a seta which is strictly dorsal, and its distolateral position in Xantharus seems a plesiomorphy of this genus only. Other unusual meristic characters for members of Scolecitrichidae are the armament of the first endopodal segment of the mandible carrying 3 setae and the first praecoxal endite of maxilla having a relatively large number of (4?)-5 setae in Xantharus (the latter condition of the maxilla is characteristic also of the Phaennidae and, thus, might have misled Andronov (1981) in his opinion that 
Xantharus belongs to this family). Both features of mandible and maxilla may also be regarded as plesiomorphic conditions and elsewhere seem to occur only in the scolecitrichid Landrumius antarcticus Park, 1983 (preaecoxal endite with 5 setae). These plesiomorphies exhibited by Xantharus seem to place this genus near the base of the Scolecitrichidae.

Xantharus differs considerably from the other scolecitrichid genera in the short length and the structure of the antennule, particularly the shortened free segments 19 and 20, and the armature of segments 18 and 19, both carrying a very long seta, which together constitute an apomorphy of this genus. This character state distinguishes Xantharus from remaining scolecitrichid genera and provides sufficient justification for its distinct generic status.

Acknowledgements. Grateful thanks are due to Dr. Sigrid Schiel (AWI, Bremerhaven) who provided me with the interesting material, and to Dr. Nina Vyshkvartzeva (Zoological Institute, Marine Biology Laboratory, St. Petersburg) for re-examination of the type material of $X$. formosus.

\section{LITERATURE CITED}

Andronov, V. N., 1981. Xantharus formosus gen. et sp. n. (Copepoda, Calanoida) from the north-west Atlantic. - Zool. Zh. 60, 1719-1722.

Bradford, J. M., Haakonssen, L. \& Jillett, J. B., 1983. The marine fauna of New Zealand: pelagic calanoid copepods: families Euchaetidae, Phaennidae, Scolecithricidae, Diaixidae, and Tharybidae. - Mem. N.Z. oceanogr. Inst. 90,1-150.

Ferrari, F. D. \& Markhaseva, E. L., 1996. Parkius karenwisherae, a new genus and species of calanoid copepod (Parkiidae, new family) from benthopelagic waters of the eastern tropical Pacific Ocean. - Proc. biol. Soc. Washington 109, 264-285.

Hulsemann, K., 1985. A new species of Neoscolecithrix Canu (Copepoda, Calanoida) in Antarctic water with remarks on the genus. - Polar Biol. 5, 55-62.

Huys, R. \& Boxshall, G. A., 1991. Copepod evolution. The Ray Society, London, 468 pp.

Park, T., 1983. Calanoid copepods of some scolecithricid genera from Antarctic and subantarctic waters. Biology of the Antarctic Seas. XIII.- Antarct. Res. Ser. 38, 165-213.

Piatkowski, U., 1983. Joint biological expedition on RRS "John Biscoe", February 1982. II. Data of micronecton and zooplankton hauls. - Ber. Polarforsch, 11, 1-40.

Vyshkvartzeva, N. V., 1989. Puchinia obtusa gen. et sp. n. (Copepoda, Calanoida) from the ultraabyssal of the Kuril-Kamchatsk Trench and the place of the genus in the family Scolecithricidae. - Zool. Zh. 68, 29-38. 